\title{
Routine Ultrasound and Limited Computed Tomography for the Diagnosis of Acute Appendicitis
}

\author{
Boudewijn R. Toorenvliet • Fraukje Wiersma • \\ Rutger F. R. Bakker · Jos W. S. Merkus • \\ Paul J. Breslau · Jaap F. Hamming
}

Published online: 26 June 2010

(C) The Author(s) 2010. This article is published with open access at Springerlink.com

\begin{abstract}
Background Acute appendicitis continues to be a challenging diagnosis. Preoperative radiological imaging using ultrasound (US) or computed tomography (CT) has gained popularity as it may offer a more accurate diagnosis than classic clinical evaluation. The optimal implementation of these diagnostic modalities has yet to be established. The aim of the present study was to investigate a diagnostic pathway that uses routine US, limited CT, and clinical re-evaluation for patients with acute appendicitis.

Methods A prospective analysis was performed of all patients presenting with acute abdominal pain at the emergency department from June 2005 until July 2006 using a structured diagnosis and management flowchart. Daily practice was mimicked, while ensuring a valid assessment of clinical and radiological diagnostic accuracies and the effect they had on patient management.

Results A total of 802 patients were included in this analysis. Additional radiological imaging was performed in $96.3 \%$ of patients with suspected appendicitis $(n=164)$. Use of CT was kept to a minimum (17.9\%), with a US:CT ratio of approximately $6: 1$. Positive and negative predictive values for the clinical diagnosis of appendicitis were 63
\end{abstract}

B. R. Toorenvliet $(\bowtie) \cdot$ P. J. Breslau · J. F. Hamming Department of Surgery, Leiden University Medical Centre, P.O. Box 9600, 2300 RC Leiden, The Netherlands

e-mail: br.toorenvliet@tiscali.nl

F. Wiersma

Department of Radiology, HAGA Hospital,

P.O. Box 40551, 2504 LN Den Haag, The Netherlands

R. F. R. Bakker · J. W. S. Merkus

Department of Surgery, HAGA Hospital,

P.O. Box 40551, 2504 LN Den Haag, The Netherlands and 98\%, respectively; for US 94 and 97\%, respectively; and for CT 100 and $100 \%$, respectively. The negative appendicitis rate was $3.3 \%$, the perforation rate was $23.5 \%$, and the missed perforated appendicitis rate was $3.4 \%$. No (diagnostic) laparoscopies were performed.

Conclusions A diagnostic pathway using routine US, limited CT, and clinical re-evaluation for patients with acute abdominal pain can provide excellent results for the diagnosis and treatment of appendicitis.

\section{Introduction}

Acute appendicitis is the most common indication for emergency abdominal surgery in patients presenting with acute abdominal pain at the emergency department (ED), with over 250.000 patients being operated for presumed appendicitis in the United States each year [1]. Traditionally, acute appendicitis has always been a clinical diagnosis based on patient history, physical examination, and laboratory testing. An active strategy with a low exploration threshold for patients with suspected appendicitis was regarded as good practice. A high percentage of negative appendectomies (20\%) was considered reasonable, based on the premise that delay would inevitably lead to perforated appendicitis and thus increased morbidity and even mortality [2].

This classical practice is currently being abandoned by most surgeons, as negative appendectomies are no longer considered acceptable. They carry a substantial morbidity, increase hospital costs [1, 3, 4], and may be avoided by using preoperative radiological imaging [5] or diagnostic laparoscopy [6, 7]. Preoperative imaging has gained wide acceptance due to the improved diagnostic accuracy, with computed tomography (CT) outperforming ultrasound 
(US) in most studies [8-10]. Diagnostic laparoscopy for the evaluation of patients with acute abdominal pain or suspected appendicitis is also increasingly employed [11-13] The diagnostic modalities, however, that are considered to be the most accurate for making the diagnosis appendicitis, such as CT and laparoscopy, also have negative repercussions. Computed tomography exposes the patient to considerable ionizing radiation, and laparoscopy is an invasive procedure performed under general anesthesia and thus carries a risk of morbidity.

Quality assurance for patients with suspected appendicitis should aim to minimize the negative appendectomy rate without a delay in the treatment of perforated appendicitis (i.e., false negative diagnoses for patients that have perforated appendicitis). The use of noninvasive modalities such as clinical evaluation, liberal use of US, and clinical re-evaluation should be the preferred method for diagnosing acute appendicitis. Therefore a diagnostic strategy for appendicitis was tested using noninvasive methods with minimal use of complementary CT (ionizing radiation) and diagnostic laparoscopy.

\section{Methods}

The present study was performed in a middle-sized teaching hospital with a 24-h emergency service with surgery, radiology, intensive care, and on call consultants in pediatrics, gynecology, and internal medicine. All consecutive patients with acute abdominal pain evaluated at the ED by a resident of the surgical department between June 2005 and July 2006 were included in the study. The surgical resident always made the primary assessment, and the consultant surgeon evaluated the patient if necessary.
Patients who were evaluated at another hospital for the same complaint, patients with abdominal pain due to trauma, and those who had undergone additional radiological examination (US or CT) prior to surgical consultation were excluded. All patients followed a structured diagnostic and management strategy algorithm (Fig. 1). First, a "clinical diagnosis" (D1) was made based on the patient's history, physical examination, and biochemical blood and urine analysis. At our hospital it is not common practice to use clinical scores for appendicitis, and residents were not asked to do so for this study. An initial management proposal (S1) was then made based on the clinical diagnosis. All clinical parameters, the clinical diagnosis (D1) and strategy (S1) were registered on a study form. After conferring with the consulting surgeon about each case (mostly over the phone), a decision was made whether or not to perform additional radiological examination. Suspected appendicitis was always considered an indication for additional imaging, and US was always the primary examination of choice. It was, however, at the radiologist's discretion to decide if CT would be a more suitable primary examination when taking into account the patient characteristics (i.e., a high BMI) and the nature of the suspected condition (e.g., acute mesenteric ischemia). When an US was inconclusive, a CT of the abdomen was subsequently made. All US and CT examinations were performed by 1 of 5 certified radiologists with similar levels of experience. For US, the abdomen was examined with an ATL HDI 5000 US system (Philips Medical Systems). All abdominal organs were examined, with special attention to the appendix, using the graded compression technique [14]. For CT a GE LightSpeed QX/i 4-slice CT (Milwaukee, WI) was used. The scan parameters were as follows: helical, rotation time $0.8 \mathrm{~s}$, slice thickness/speed:
Fig. 1 Study design for patients presenting with abdominal pain at the emergency department for surgical consultation

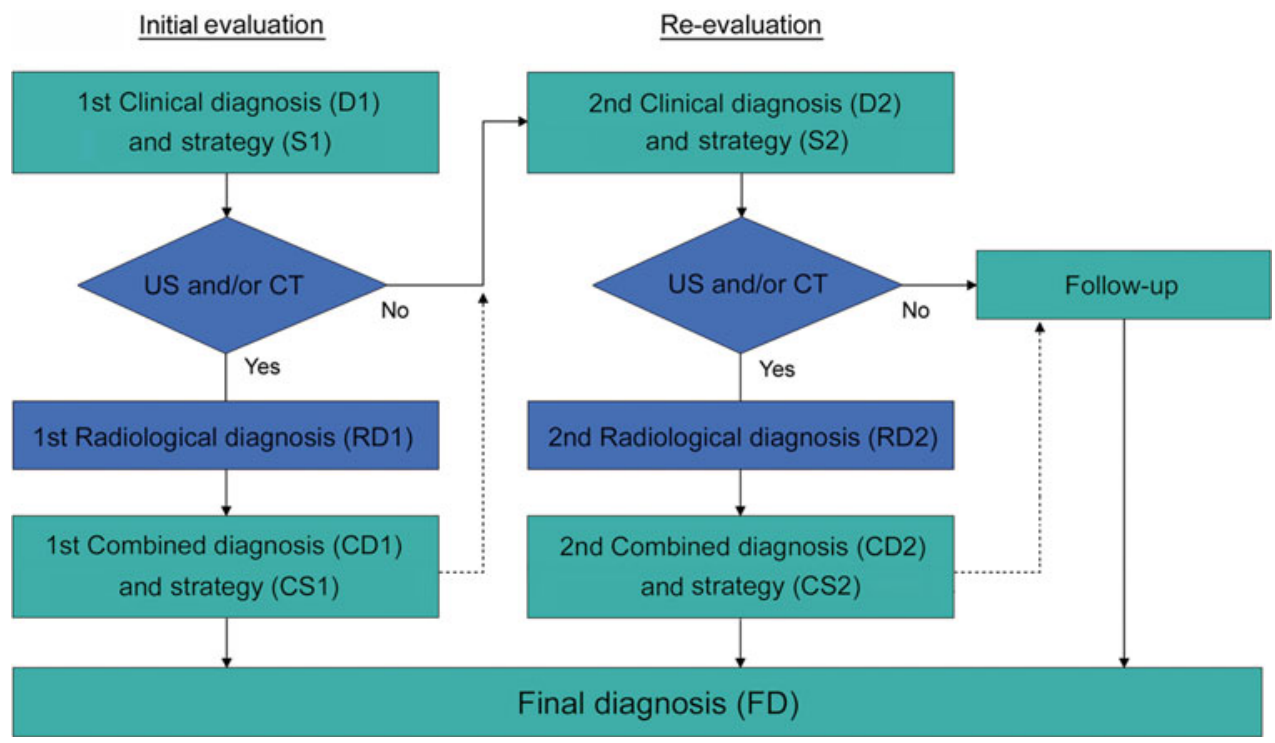


$5.0 \mathrm{~mm} / 22.5 \mathrm{~mm} \mathrm{HS}$, interval $5.0 \mathrm{~mm}, 120 \mathrm{kV}, 250 \mathrm{~mA}$, from diaphragm to pubic symphysis. Intravenous (Xenetix 300 [Guerbet, France], $100 \mathrm{cc}, 2 \mathrm{cc} / \mathrm{s}$, delay $70 \mathrm{~s}$ [portal phase], via an infusion pump) or rectal (Xenetix 300 3\% [diluted with tap water], 11 via rectal cannula was administered just prior to scanning) contrast was only given if the appendix could not be accurately visualized on a plain CT. No reformats were made. After hearing the radiological result (RD1), the initial clinical diagnosis and strategy were reassessed in the light of this result by the resident and the surgeon, and consequently altered if necessary (CD1 \& CS1). Again all results and considerations were registered on the study form. Patients were admitted to the hospital if they were thought to have an abdominal condition that required immediate operation or medical therapy necessitating admission. All patients that were not admitted to the surgical ward after surgical consultation at the ED were given appointments for re-evaluation at the outpatient clinic within $24 \mathrm{~h}$. There, the diagnosis and management strategies were reassessed (D2 and S2) by the consultant surgeon or a surgical resident under the supervision of a consultant surgeon. Additional radiological examinations were carried out if deemed necessary. Patients were discharged from outpatient follow-up only when a definitive diagnosis was made and the treatment was successfully initiated or completed, or if the patient no longer had abdominal complaints. The final diagnosis (FD) was based on intraoperative findings or pathological examination of the resected organs. If patients did not undergo an operation, the final diagnosis was made by the clinical and/or radiological diagnosis in combination with the clinical response to medical therapy at standard re-evaluation and follow-up as described above.

After conclusion of the study all hospital records were reviewed by two surgical residents (B.T. and R.B.), who double-checked the data and verified the final diagnoses for all patients in the database. Patients were excluded from analysis if they did not show up for the re-evaluation appointment or if the study form was missing or incomplete. For all these patients, the hospital records were searched and patients were contacted for additional information. If the patients were not successfully contacted, the general practitioner was consulted for the patient's medical records. Complications during hospital admission were scored twice daily in a prospective database as reported earlier [15]. Statistical analysis was performed with SPSS 16.0.

\section{Results}

During the study period 972 patients were evaluated. Of these, 49 patients $(5.0 \%)$ were excluded when they did not show up for their re-evaluation appointment, and another
$121(12.4 \%)$ patients were excluded as their study forms were missing or incomplete. For 23 of these patients no follow-up details were acquired (2.4\%). Of the 147 patients excluded from analysis for whom follow-up was successful, seven had acute appendicitis and were treated at our own hospital. They were excluded because the study forms were missing or incomplete and therefore the effect of diagnostics on management could not be assessed. In total, 802 patients were eligible for analysis.

Of the 802 patients eligible for analysis, $483(60.2 \%)$ were evaluated at the $\mathrm{ED}$ at the request of a general practitioner (416) or a consultant from another specialty (67). All other patients came to the hospital of their own accord. Suspected acute appendicitis was the most frequent reason for consultation for abdominal pain $(51.8 \%)$. Of the 250 patients who had appendicitis as the referring diagnosis, $78(31.2 \%)$ were ultimately determined to have appendicitis (FD).

\section{Suspected appendicitis}

After primary evaluation at the ED, 164 patients were suspected to have appendicitis (D1). The mean Alvarado score [16] could be calculated retrospectively using the clinical parameters obtained at initial evaluation. This was 6.5 (SD 1.9). The proposed strategy (S1) was an open appendectomy 99 times, an admission to the hospital for re-evaluation 32 times, and an outpatient re-evaluation the next day 33 times. Diagnostic laparoscopy was never proposed. A total of 139 patients underwent additional radiological imaging after the primary evaluation. Of these, 117 patients had US only, 2 patients had CT only, and 20 patients had US as well as CT. Twenty-five patients did not undergo additional radiological imaging on the day of the primary evaluation. Six patients did not because they had mild symptoms (mean Alvarado score: 5.2), 16 patients were planned for additional radiological imaging the next day (mean Alvarado score: 5.8), and 3 patients were operated directly as the suspicion for acute appendicitis was very high (mean Alvarado score: 9.0). These 3 patients all had acute appendicitis (FD). Three of the 22 remaining patients did not undergo additional radiological imaging the next day as the clinical suspicion for appendicitis at re-evaluation was minimal. The final diagnosis was viral gastroenteritis for all three. Therefore 158 of the 164 patients (96.3\%) clinically suspected to have appendicitis had additional radiological imaging. Ten patients underwent additional imaging on both days, and only 29 patients (18.4\%) underwent a CT examination of the abdomen. It was never necessary to procure a CT for a single patient on both days.

One hundred and four of the 164 patients $(63.4 \%)$ had acute appendicitis as the final diagnosis (Fig. 2). Table 1 gives an overview of the final diagnoses of the 60 other 


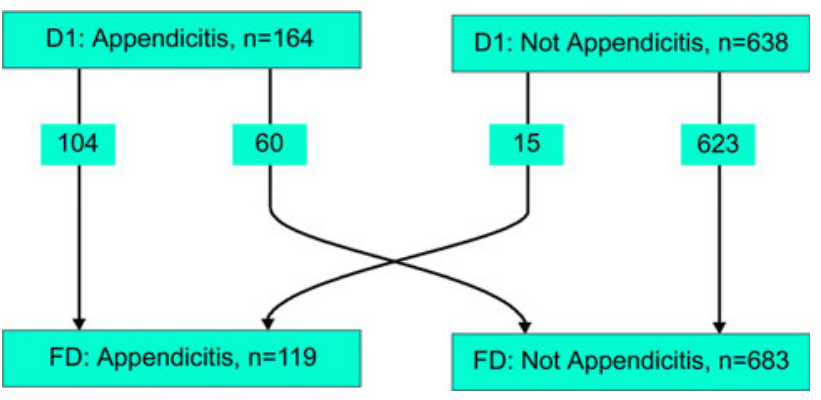

Fig. 2 Diagnostic changes between the clinical diagnosis at initial evaluation (D1) and the final diagnosis (FD)

Table 1 Final diagnoses (FD) for patients that were incorrectly suspected to have appendicitis after primary clinical evaluation (D1)

\begin{tabular}{lrr}
\hline & $\mathrm{N}$ & $\%$ \\
\hline Nonspecific mesenteric lymphadenitis & 19 & 31.7 \\
Viral intestinal infection, unspecified & 11 & 18.3 \\
Other and unspecified abdominal pain & 10 & 16.7 \\
Non-inflamed appendix (at operation) & 4 & 6.7 \\
Diverticular disease of intestine & 3 & 5.0 \\
Gastritis and duodenitis & 2 & 3.3 \\
Constipation & 2 & 3.3 \\
Pancreatitis & 2 & 3.3 \\
Bronchitis, not specified as acute or chronic & 1 & 1.7 \\
Perforation of intestine (nontraumatic) & 1 & 1.7 \\
Spontaneous bacterial peritonitis & 1 & 1.7 \\
Calculus of kidney and ureter & 1 & 1.7 \\
Meckel's diverticulitis (at operation) & 1 & 1.7 \\
Ileocecitis & 1 & 1.7 \\
Epiploic appendagitis & 1 & 1.7 \\
Total & 60 & 100 \\
\hline
\end{tabular}

patients that did not have appendicitis. Table 2 shows the diagnostic accuracies for the clinical diagnosis acute appendicitis in this series of patients.
Additional radiological imaging

Of the 802 patients in the study, 577(71.9\%) had a total of 599 additional radiological examinations. Twenty-two patients had additional radiological imaging on both days. Table 2 shows the diagnostic accuracies of additional radiological imaging for appendicitis, and Table 3 shows the number of radiological examinations performed. There were 6 false positive results and 9 false negative results. All errors were the result of US examinations.

With respect to making the diagnosis of acute appendicitis, additional radiological examination gave the correct diagnosis $97.5 \%$ of the time. In the hypothetical case that the radiological result should always be conclusive, the strategy befitting the radiological result (i.e., appendicitis: operation, not appendicitis: no operation for appendicitis) would have been correct in $97.7 \%$. A change in strategy should have then been made for 96 of the 599 patients $(16.0 \%)$ with respect to the diagnosis and management of appendicitis. Eighty-seven (90.6\%) of these changes would have been correct, and two-thirds thereof would have been considered major (i.e., from a conservative treatment to an operation or vice versa).

Five hundred and ninety-one times (98.7\%), the diagnosis made and the strategy taken by the surgeon after hearing the radiological result (CS1 or CS2) was the same strategy that befitted the radiological diagnosis "appendicitis" or "not appendicitis." This was correct 582 times (98.5\%), but incorrect in 9 cases (1.5\%). Three patients had a non-inflamed appendix at operation on the first day, and for six patients appendicitis was not diagnosed by US on the first day. These patients were all operated the following day; three patients had a phlegmonous appendicitis and 3 had perforated appendicitis. Four of these six patients were suspected to have appendicitis at first evaluation.

Eight times (1.3\%) the diagnosis made and strategy taken by the surgeon after hearing the radiological result was different from the strategy that befitted the radiological

Table 2 Diagnostic accuracies for the diagnosis appendicitis

\begin{tabular}{|c|c|c|c|c|c|c|c|c|c|c|}
\hline & $\mathrm{TP}$ & FP & FN & $\mathrm{TN}$ & Sens & Spec & PPV & NPV & $\mathrm{LR}+$ & LR- \\
\hline \multicolumn{11}{|l|}{ Clinical diagnosis } \\
\hline$N=802$ & 104 & 60 & 15 & 623 & 0.87 & 0.91 & 0.63 & 0.98 & 10 & 0.14 \\
\hline Female (12-51 years of age) & 25 & 14 & 5 & 179 & 0.83 & 0.93 & 0.64 & 0.97 & 11 & 0.18 \\
\hline Male (12-51 years of age) & 37 & 12 & 2 & 97 & 0.95 & 0.89 & 0.76 & 0.98 & 9 & 0.06 \\
\hline US only & 94 & 6 & 9 & 310 & 0.91 & 0.98 & 0.94 & 0.97 & 48 & 0.09 \\
\hline CT only & 4 & 0 & 0 & 90 & 1.0 & 1.0 & 1.0 & 1.0 & Inf & 0.0 \\
\hline US and CT only & 14 & 0 & 0 & 61 & 1.0 & 1.0 & 1.0 & 1.0 & Inf & 0.0 \\
\hline US and/or CT & 113 & 6 & 9 & 471 & 0.93 & 0.99 & 0.95 & 0.98 & 74 & 0.07 \\
\hline
\end{tabular}

$T P$ true positive; $F P$ false positive; $F N$ false negative; $T N$ true negative; Sens sensitivity; Spec specificity; $P P V$ positive predictive value; $N P V$ negative predictive value; $L R+$ positive likelihood ratio; $L R$ - negative likelihood ratio; $U S$ ultrasound; $C T$ computed tomography 
Table 3 Number of additional radiological examinations performed

\begin{tabular}{lrrrrr}
\hline & R1 & R2 & R1\&2 & $\begin{array}{l}\text { Total number } \\
\text { of patients }\end{array}$ & $\begin{array}{l}\text { Total number } \\
\text { of examinations }\end{array}$ \\
\hline US only & 257 & 162 & 14 & 405 & 419 \\
CT only & 42 & 52 & 2 & 92 & 94 \\
US and CT only & 54 & 21 & 0 & 75 & 75 \\
US and/or CT & 358 & 241 & 22 & 577 & 599 \\
\hline
\end{tabular}

$R 1$ number of patients that had radiological examinations at initial evaluation; $R 2$ number of patients that had radiological examinations at re-evaluation; $R 1 \& 2$ number of patients that had radiological examinations on both days

diagnosis. This was correct in 7 cases $(87.5 \%)$, and incorrect in one (12.5\%). Three patients assumed not to have appendicitis after US of the abdomen were operated nonetheless. All three patients had appendicitis. Two patients were not operated after the radiological result "appendicitis," and both had self-limiting abdominal pain at follow-up. Two patients that were thought by the radiologist to have an appendicular mass, and could therefore be treated conservatively, were both operated. One of these patients underwent an open appendectomy and was found to have a generalized purulent peritonitis due to perforated appendicitis. She had a postoperative ileus that was treated conservatively. The other patient had transrectal drainage of an appendicular abscess and was discharged from the hospital without complications.

The patient for whom the radiological diagnosis was incorrectly overruled had a non-inflamed appendix at operation.

\section{Confirmed appendicitis}

Of the 802 patients studied, 119 had appendicitis (14.8\%). The demographics, clinical parameters, and pathological findings are presented in Table 4. All resected appendices were subjected to pathological examination. The pathologic criteria for acute appendicitis were an absence of mucosal epithelium in combination with transmural infiltration (of lymphocytes and neutrophilic granulocytes) extending towards the serosal surface and/or into the adjacent fat.

One hundred and sixteen of the 119 patients (97.5\%) had additional radiological imaging, 100 patients on the first day, 22 at re-evaluation, and 6 patients on both days. A total of 118 US studies and 19 CT studies were made. No diagnostic laparoscopies were performed.

One hundred and nineteen of the 802 patients were operated for appendicitis using an open technique through a gridiron incision. A Meckel's diverticulitis was found in one patient, and the appendix was not resected. In four other patients a non-inflamed appendix was found at operation and pathological examination confirmed this
(3.3\%). Acute appendicitis was never diagnosed (by chance) during an operation initiated under the suspicion of a disease other than appendicitis.

Four patients that were not operated on the first day after the primary evaluation had a perforated appendicitis. These are patients that should have been operated immediately and account for a missed perforated appendicitis rate of $3.4 \%$.

\section{Discussion}

The clinical appreciation of a patient with suspected appendicitis remains challenging as it is complicated by nonsurgical diseases that mimic appendicitis [17]. The accuracy of the clinical diagnosis is approximately $80 \%$, which corresponds to a negative appendectomy rate of around 20\% [18]. This flaw in diagnostic accuracy has traditionally been accepted as it was considered most important to perform an early operation. Quality assurance focused on perforated appendicitis rather than negative appendectomy rates [2]. This practice has become less accepted for several reasons: the morbidity and costs associated with a negative appendectomy are substantial [1, 3 , 4], and there is ample evidence that preoperative imaging can reduce the negative appendectomy rate [5, 19-24], and lessen the use of hospital resources [25, 26]. Even though some institutions have reported contradictory results [27-29], preoperative imaging for all patients with suspected appendicitis is gaining support [30,31]. Another reason for abandoning indiscriminate explorations for suspected appendicitis is new insights into the natural history of appendicitis. These challenge the belief that the perforated appendicitis rate is inversely related to the negative appendectomy rate and thus avoidable by urgent appendectomy [32]. Perforated appendicitis rates are not influenced by in-hospital delay [33] and have not decreased with the increasing use of CT imaging [34, 35]. Evidence suggesting that resolving appendicitis is common can clarify this phenomenon [36]. Quality assurance should therefore focus on the accuracy of the preoperative 
Table 4 Demographics, clinical parameters, and pathological findings (if the appendix was resected) for patients with a final diagnosis appendicitis $(n=119)$

\begin{tabular}{|c|c|c|c|}
\hline & Child $(<17)$ & Adult & All \\
\hline $\mathrm{N}$ & 69 & 50 & 119 \\
\hline Age (years) & $10.3(\mathrm{SD}=3.7)$ & $39.3(\mathrm{SD}=16.5)$ & $22.5(\mathrm{SD}=18.1)$ \\
\hline Female & $21(30.4)$ & $28(56.0)$ & $49(41.2)$ \\
\hline Duration of complaints (days) & $2.1(\mathrm{SD}=1.9)$ & $1.9(\mathrm{SD}=1.8)$ & $2.1(\mathrm{SD}=1.8)$ \\
\hline Nausea & $62(89.9)$ & $36(72.0)$ & $98(82.4)$ \\
\hline Vomiting & $52(75.4)$ & $17(34.0)$ & $69(58.0)$ \\
\hline Anorexia & $50(72.5)$ & $32(64.0)$ & $82(68.9)$ \\
\hline Migration of pain to RLQ & $28(40.6)$ & $16(32.0)$ & $44(37.0)$ \\
\hline Dysuria & $6^{\mathrm{a}}(8.7)$ & $4^{\mathrm{b}}(8.0)$ & $10 / 116^{\mathrm{c}}(8.6)$ \\
\hline Diarrhea & $12^{\mathrm{a}}(17.4)$ & $7^{b}(14.0)$ & $19 / 116^{\mathrm{c}}(16.4)$ \\
\hline Rebound tenderness & $38(55.1)$ & $26(52.0)$ & $64(53.8)$ \\
\hline Abdominal guarding & $20(29.0)$ & $12(24.0)$ & $32 / 117^{\mathrm{b}}(27.4)$ \\
\hline Tenderness RLQ & $62(89.9)$ & $47(94.0)$ & 109 (91.6) \\
\hline Heart rate (bpm) & $94.7(\mathrm{SD}=18.2)$ & $80.8(\mathrm{SD}=13.8)$ & $88.2(\mathrm{SD}=19.2)$ \\
\hline Temperature $\left({ }^{\circ} \mathrm{C}\right)$ & $37.5(\mathrm{SD}=0.9)$ & $37.1(\mathrm{SD}=0.7)$ & $37.3(\mathrm{SD}=0.9)$ \\
\hline Leucocytes $\left(\times 10^{9} / 1\right)$ & $14.7(\mathrm{SD}=5.5)$ & $13.5(\mathrm{SD}=4.4)$ & $14.2(\mathrm{SD}=5.1)$ \\
\hline C-reactive protein $(\mathrm{mg} / \mathrm{l})$ & $56.2(\mathrm{SD}=56.8)$ & $51.2(\mathrm{SD}=55.6)$ & $54.2(\mathrm{SD}=56.4)$ \\
\hline Erythrocyte sedimentation rate $(\mathrm{mm} / \mathrm{h})$ & $18.6(\mathrm{SD}=15.0)$ & $22.7(\mathrm{SD}=31.6)$ & $20.6(\mathrm{SD}=24.5)$ \\
\hline \multicolumn{4}{|l|}{ Operated } \\
\hline Phlegmonous/gangrenous & $45(65.2)$ & $41(82.0)$ & $86(72.3)$ \\
\hline Perforated & $23(33.3)$ & $5(10.0)$ & $28(23.5)$ \\
\hline Appendicular abscess (rectal drainage) & $1(1.4)$ & $0(0.0)$ & $1(0.8)$ \\
\hline \multicolumn{4}{|l|}{ Not operated } \\
\hline Appendicular mass & $0(0.0)$ & $4(8.0)$ & $4(3.4)$ \\
\hline
\end{tabular}

The numbers in parentheses are standard deviations (SD) for the given mean values, or percentages for the number of patients tallied

${ }^{\text {a }}$ One missing value

b Two missing values

c Three missing values

$R L Q$ right lower quadrant; $b p m$ beats per minute

diagnosis, and not on the urgency with which it is made. Negative appendectomy rates and false negative diagnoses for patients who present with perforated appendicitis should be kept to an absolute minimum.

The prospective evaluation presented in this study assessed a diagnostic pathway that used routine US, limited $\mathrm{CT}$, and clinical re-evaluation for the diagnosis and management of acute appendicitis at the ED. Clinical evaluation for patients with appendicitis had a positive and negative predictive value (PPV/NPV) of 63 and 98\%, respectively. Female patients between 12 and 51 years old $(n=223)$ had a similar diagnostic accuracy (PPV 64\%, NPV $0.97 \%$ ) when compared to the whole study population (Table 2). The diagnostic accuracy for men in the same age group $(n=148)$ was slightly better (PPV $76 \%$, NPV $0.98 \%$ ). Even so, relying on the clinical diagnosis alone would have led to an unacceptable percentage of false positive diagnoses for appendicitis. This has also been reported by a recently published prospective analysis on diagnostic accuracy for acute abdominal pain [37], and it opposes earlier publications that state otherwise [38].

Additional radiological imaging was performed in 96.3 and $97.5 \%$ of patients with suspected and confirmed appendicitis, respectively. Computed tomography use was kept to a minimum (17.9\%), with a US:CT ratio of approximately $6: 1$. Only $4 \%$ of pediatric patients that had additional imaging underwent a CT (8/200), with a US:CT ratio of 24:1. (Four had an inconclusive US, three were suspected to have intra-abdominal abscesses and an ileus on US, and for one patient the reason for the additional CT is unknown.)

The results of additional radiological imaging were excellent. With respect to the diagnosis of appendicitis, CT had a perfect score (no false negatives, no false positives.) This compares favorably to the results reported in the literature [8-10] and contradicts the earlier opinion that the 
high accuracies reported by research institutions cannot be reproduced in daily general practice [39]. The same can be said of the diagnostic accuracy of US in this study. With a sensitivity of $91 \%$ and a specificity of $98 \%$, the diagnostic accuracy was superior to those reported in a recent meta-analysis (sensitivity 78\%, specificity 83\%) [8], even outperforming CT (sensitivity 91\%, specificity 90\%). Additional imaging provided the correct diagnosis and corresponding strategy regarding appendicitis in $98 \%$ of cases. It correctly changed the diagnosis for 20 patients with suspected appendicitis for whom the initial clinical strategy was an open appendectomy (S1). Theoretically this means that the negative appendectomy rate without additional imaging would have been $16.8 \%$ (24/143) instead of $3.3 \%(4 / 123)$. This is similar to other reports on the effects of imaging on the negative appendectomy rate $[19,20,24]$. The perforation rate in this study was $23.5 \%$. This also corresponds to rates reported in the literature $[28,33]$, as well as the observation that the perforation rate was not changed by preoperative imaging [24].

No diagnostic laparoscopies were proposed or performed during this study. Some authors recommend the use of laparoscopy for the diagnosis of acute abdominal pain $[12,13,40]$ and suspected appendicitis [6, 7]. The guidelines of the European Association for Endoscopic Surgery state that diagnostic laparoscopy can be useful for patients with acute abdominal pain, but that noninvasive diagnostic aids should be exhausted first [41]. With a negative appendectomy rate of $3.3 \%$ and a missed perforated appendicitis rate of $3.4 \%$, we do not believe that diagnostic laparoscopy would have provided a diagnostic advantage in this study.

During study design, several measures were taken to ensure that an accurate assessment could be made of the diagnostic performance of clinical evaluation and additional imaging, and more importantly, what impact they would have in decision making. Here, an attempt has been made to mimic daily practice by studying an unselected population of ED patients with a realistic sample prevalence of appendicitis. Patients were evaluated by residents with over the phone consultation prior to additional imaging. This is common practice at our hospital, as not all patients are seen by a consultant surgeon before additional imaging. Both adults and children were investigated in the same study, as there are no differences in the diagnostic pathway, apart from the fact that CT is rarely used for the evaluation of children. A well-accepted and valid reference standard was used (pathological findings and clinical follow-up), and all patients had an adequate follow-up, even those who were excluded from analysis. This was done to ensure that no false negative diagnoses were missed. A limitation of this study is that it represents only a single center's experience.
The presented results can be considered encouraging and support the diagnostic strategy that imaging should be routine for all patients with suspected appendicitis, and not just for equivocal cases [31, 37, 42]. Although CT had a higher diagnostic accuracy, we believe that US should be the primary investigation for all patients with suspected appendicitis, as others investigators have stated before [30, 37]. Ultrasound is safe, easily accessible, and, most important, does not use ionizing radiation. When the US result is equivocal a CT should be carried out. A negative US result does not justify a complementary CT. Patients with an equivocal clinical diagnosis and a negative US for appendicitis, can safely be re-evaluated during a hospital admission or at the outpatient clinic the next day. In case of non-visualization of the appendix during US in children, appendicitis can be safely ruled out if there are no secondary signs of appendicitis [43].

The consequences of routine imaging for patients with potentially resolving appendicitis goes beyond the scope of this study. Future investigations will have to focus on this issue.

Having said all this, it must not be forgotten that thorough clinical evaluation is the cornerstone of every ED assessment for a patient with acute abdominal pain. In 7 out of 8 cases in which the radiological diagnosis was overruled, the surgeon did so rightly. The radiological result must always be interpreted in light of the clinical assessment of the patient.

\section{Conclusions}

Clinical evaluation alone is not accurate enough to manage patients with suspected appendicitis adequately. A diagnostic pathway using routine US, limited CT, and clinical re-evaluation for patients with acute abdominal pain provided excellent results for the diagnosis and treatment of appendicitis. The use of ionizing radiation was minimal and diagnostic laparoscopy was unnecessary to achieve these results.

Open Access This article is distributed under the terms of the Creative Commons Attribution Noncommercial License which permits any noncommercial use, distribution, and reproduction in any medium, provided the original author(s) and source are credited.

\section{References}

1. Flum DR, Koepsell T (2002) The clinical and economic correlates of misdiagnosed appendicitis: nationwide analysis. Arch Surg 137:799-804

2. Velanovich V, Satava R (1992) Balancing the normal appendectomy rate with the perforated appendicitis rate: implications for quality assurance. Am Surg 58:264-269 
3. Leung TT, Dixon E, Gill M et al (2009) Bowel obstruction following appendectomy: what is the true incidence? Ann Surg 250:51-53

4. Bijnen CL, van den Broek WT, Bijnen AB et al (2003) Implications of removing a normal appendix. Dig Surg 20:215-219

5. Rao PM, Rhea JT, Rattner DW et al (1999) Introduction of appendiceal CT: impact on negative appendectomy and appendiceal perforation rates. Ann Surg 229:344-349

6. Moberg AC, Ahlberg G, Leijonmarck CE et al (1998) Diagnostic laparoscopy in 1043 patients with suspected acute appendicitis. Eur J Surg 164:833-840

7. Sauerland S, Lefering R, Neugebauer EA (2004) Laparoscopic versus open surgery for suspected appendicitis. Cochrane Database Syst Rev (4)CD001546

8. van RA, Bipat S, Zwinderman AH et al (2008) Acute appendicitis: meta-analysis of diagnostic performance of $\mathrm{CT}$ and graded compression US related to prevalence of disease. Radiology 249:97-106

9. Doria AS, Moineddin R, Kellenberger CJ et al (2006) US or CT for diagnosis of appendicitis in children and adults? A metaanalysis. Radiology 241:83-94

10. Terasawa T, Blackmore CC, Bent S et al (2004) Systematic review: computed tomography and ultrasonography to detect acute appendicitis in adults and adolescents. Ann Intern Med 141:537-546

11. Chung RS, Diaz JJ, Chari V (1998) Efficacy of routine laparoscopy for the acute abdomen. Surg Endosc 12:219-222

12. Golash V, Willson PD (2005) Early laparoscopy as a routine procedure in the management of acute abdominal pain-a review of 1, 320 patients. Surg Endosc 19:882-885

13. Al-Mulhim AS, Nasser MA, Abdullah MM et al (2008) Emergency laparoscopy for acute abdominal conditions: a prospective study. J Laparoendosc Adv Surg Tech A 18:599-602

14. Puylaert JB (1986) Acute appendicitis: US evaluation using graded compression. Radiology 158:355-360

15. Veen MR, Lardenoye JW, Kastelein GW et al (1999) Recording and classification of complications in a surgical practice. Eur J Surg 165:421-424

16. Alvarado A (1986) A practical score for the early diagnosis of acute appendicitis. Ann Emerg Med 15:557-564

17. Breda Vriesman AC, Puylaert JB (2006) Mimics of appendicitis: alternative nonsurgical diagnoses with sonography and CT. AJR Am J Roentgenol 186:1103-1112

18. Birnbaum BA, Wilson SR (2000) Appendicitis at the millennium. Radiology 215:337-348

19. Jones K, Pena AA, Dunn EL et al (2004) Are negative appendectomies still acceptable? Am J Surg 188:748-754

20. Raman SS, Osuagwu FC, Kadell B et al (2008) Effect of CT on false positive diagnosis of appendicitis and perforation. N Engl J Med 358:972-973

21. Bendeck SE, Nino-Murcia M, Berry GJ et al (2002) Imaging for suspected appendicitis: negative appendectomy and perforation rates. Radiology 225:131-136

22. Guss DA, Behling CA, Munassi D (2008) Impact of abdominal helical computed tomography on the rate of negative appendicitis. J Emerg Med 34:7-11

23. Wilson EB, Cole JC, Nipper ML et al (2001) Computed tomography and ultrasonography in the diagnosis of appendicitis: when are they indicated? Arch Surg 136:670-675

24. Wagner PL, Eachempati SR, Soe K et al (2008) Defining the current negative appendectomy rate: for whom is preoperative computed tomography making an impact? Surgery 144:276282
25. Rao PM, Rhea JT, Novelline RA et al (1998) Effect of computed tomography of the appendix on treatment of patients and use of hospital resources. N Engl J Med 338:141-146

26. Pena BM, Taylor GA, Fishman SJ et al (2000) Costs and effectiveness of ultrasonography and limited computed tomography for diagnosing appendicitis in children. Pediatrics 106:672-676

27. Frei SP, Bond WF, Bazuro RK et al (2008) Appendicitis outcomes with increasing computed tomographic scanning. Am J Emerg Med 26:39-44

28. Flum DR, Morris A, Koepsell T et al (2001) Has misdiagnosis of appendicitis decreased over time? A population-based analysis. JAMA 286:1748-1753

29. Chiang DT, Tan EI, Birks D (2008) "To have...or not to have". Should computed tomography and ultrasonography be implemented as a routine work-up for patients with suspected acute appendicitis in a regional hospital? Ann R Coll Surg Engl 90:17-21

30. Gaitini D, Beck-Razi N, Mor-Yosef D et al (2008) Diagnosing acute appendicitis in adults: accuracy of color Doppler sonography and MDCT compared with surgery and clinical follow-up. AJR Am J Roentgenol 190:1300-1306

31. Puig S, Staudenherz A, Felder-Puig R et al (2008) Imaging of appendicitis in children and adolescents: useful or useless? A comparison of imaging techniques and a critical review of the current literature. Semin Roentgenol 43:22-28

32. Andersson RE (2007) The natural history and traditional management of appendicitis revisited: spontaneous resolution and predominance of prehospital perforations imply that a correct diagnosis is more important than an early diagnosis. World J Surg 31:86-92

33. Colson M, Skinner KA, Dunnington G (1997) High negative appendectomy rates are no longer acceptable. Am J Surg 174: $723-726$

34. Livingston EH, Woodward WA, Sarosi GA et al (2007) Disconnect between incidence of nonperforated and perforated appendicitis: implications for pathophysiology and management. Ann Surg 245:886-892

35. Cuschieri J, Florence M, Flum DR et al (2008) Negative appendectomy and imaging accuracy in the Washington State Surgical Care and Outcomes Assessment Program. Ann Surg 248:557-563

36. Andersson RE (2008) Resolving appendicitis is common: further evidence. Ann Surg 247:553

37. Lameris W, van RA, van Es HW et al (2009) Imaging strategies for detection of urgent conditions in patients with acute abdominal pain: diagnostic accuracy study. BMJ 338:b2431

38. Lee SL, Walsh AJ, Ho HS (2001) Computed tomography and ultrasonography do not improve and may delay the diagnosis and treatment of acute appendicitis. Arch Surg 136:556-562

39. Flum DR, McClure TD, Morris A et al (2005) Misdiagnosis of appendicitis and the use of diagnostic imaging. J Am Coll Surg 201:933-939

40. Vander Velpen GC, Shimi SM, Cuschieri A (1994) Diagnostic yield and management benefit of laparoscopy: a prospective audit. Gut 35:1617-1621

41. Sauerland S, Agresta F, Bergamaschi R et al (2006) Laparoscopy for abdominal emergencies-evidence-based guidelines of the European Association for Endoscopic Surgery. Surg Endosc 20:14-29

42. Paulson EK, Kalady MF, Pappas TN (2003) Clinical practice. Suspected appendicitis. N Engl J Med 348:236-242

43. Wiersma F, Toorenvliet BR, Bloem JL et al (2009) US examination of the appendix in children with suspected appendicitis: the additional value of secondary signs. Eur Radiol 19:455-461 